\title{
In situ neutron scattering of antibody adsorption during protein A chromatography
}

\author{
Maria Papachristodoulou ${ }^{1}$, James Doutch ${ }^{2}$, Hoi Sang Beatrice Leung ${ }^{1}$, Andy Church', Thomas \\ Charleston $^{2}$, Luke A. Clifton ${ }^{2}$, Paul D. Butler ${ }^{3,4,5}$, Christopher J. Roberts ${ }^{4}$ and Daniel G. Bracewell ${ }^{1}$ \\ ${ }^{I}$ Department of Biochemical Engineering, University College London, Gower Street, London, UK, WCIE 6BT \\ ${ }^{2}$ ISIS, Rutherford Appleton Laboratory, Harwell Science and Innovation Campus, Didcot, Oxon, OX11 OQX \\ ${ }^{3}$ NIST Center for Neutron Research, National Institute of Standards and Technology, 100 Bureau Dr, Gaithersburg, MD, USA \\ ${ }^{4}$ Department of Chemical and Biomolecular Engineering, University of Delaware, Newark, DE, USA \\ ${ }^{5}$ Department of Chemistry, The University of Tennessee Knoxville, Knoxville, TN, USA
}

Corresponding author: Daniel G. Bracewell, d.bracewell@ucl.ac.uk, +44 (0)20 76799580

Keywords: Protein A, Small Angle Neutron Scattering, Antibody, Chromatography, Adsorption, Interface

\begin{abstract}
A deeper understanding of the nanoscale and mesoscale structure of chromatographic adsorbents and the distribution of proteins within the media, is critical to a mechanistic understanding of separation processes using these materials. Characterisation of the media's architecture at this scale and protein adsorption within, is challenging using conventional techniques. In this study, we propose a novel resin characterisation technique that enables in-situ measurement of the structure of the adsorbed protein layer within the resin, under typical chromatographic conditions. A quartz flow-through cell was designed and fabricated for use with Small Angle Neutron Scattering (SANS), in order to measure the nanoscale to mesoscale structures of a silica based protein A chromatography resin during the monoclonal antibody sorption process. We were able to examine the pore-to-pore ( $\sim 133 \mathrm{~nm})$ and pore size $(\sim 63 \mathrm{~nm})$ correlations of the resin and the in-plane adsorbed antibody molecules $(\sim 4.2 \mathrm{~nm}$ ) correlation at different protein loadings and washing buffers, in real time using a contrast matching approach. When $0.03 \mathrm{M}$ sodium phosphate with $1 \mathrm{M}$ urea and $10 \%$ isopropanol buffer, $\mathrm{pH} 8$, was introduced into the system as a wash buffer, it disrupted the system's order by causing partial unfolding of the adsorbed antibody, as evidenced by a loss of the in-plane protein correlation. This method offers new ways to investigate the nanoscale structure and ligand immobilisation within chromatography resins; and perhaps most importantly understand the in-situ behaviour of adsorbed proteins within the media under different mobile phase conditions within a sample environment replicating that of a chromatography column.
\end{abstract}




\section{Introduction}

In commercial separations for therapeutic proteins, binding capacity is a critical factor. An example of such a process is protein A-based affinity chromatography, which is the crucial purification stage for monoclonal antibodies. Maximised binding capacity leads to improved productivity, which in turn leads to better process intensification (PI). Although PI is ultimately the goal for several scaleup procedures, product stability and quality must always be maintained. It is widely accepted that low $\mathrm{pH}$ in such processes leads to increased aggregation propensity [1-3]. This increase in aggregation is likely to contribute to the enhanced interaction with Fcg Receptors observed by Lopez et al. [4]. They also highlight that IgG purification methods can alter the Fcg Receptors binding behaviour and biological activity significantly, and that the purification approach selected might be a contributing factor to the pure reproducibility across current assays employed to evaluate Fc-mediated antibody effector functions [4]. However, $\mathrm{pH}$ is not the only parameter that can affect aggregation levels. Structural stability of the eluted IgG can be jeopardized by protein A, making at least a subpopulation of eluted Immunoglobulin $G(I g G)$ more prone to aggregation. This can be attributed to the protein A destabilising effect (conformational relaxation) on the upper portion of IgG's second constant domain [5,6], in addition to the denaturing effects of low $\mathrm{pH}$. Gagnon et al. have demonstrated that during the protein A chromatographic elution step. Size and conformation of the IgG1 ( $150 \mathrm{kDa})$ undergo significant changes due to protein $A$ mediated (42 kDa) denaturation, $\mathrm{pH}$, ionic strength and high $\operatorname{lgG}$ concentrations $[7,8]$. It is suggested that the decrease in hydrodynamic radius of the $\lg \mathrm{G} 1$ molecules in solution arises predominantly from the propensity of IgG to adopt smaller conformations at higher concentrations, low pH and ionic strength. However, when binding to protein $A$, an increase in IgG size accompanied the loss of secondary structure. This change was attributed to the excess $\alpha$-helices, extending the hydrodynamic axis of the protein. The high degree of changes in the secondary structure appeared to result from the dual-site interaction between both IgG heavy chains and distinct protein $A$ molecules (one IgG is bound to two protein A molecules) [8]. Other studies from Shukla et al. and Mazzer et al. also support that adsorption / binding to the protein A resin has a destabilizing effect on the antibody molecules and promotes the formation of aggregation-prone species. They quantified the increase in aggregation rate following low $\mathrm{pH}$ elution from a protein $\mathrm{A}$ column, which was significantly higher when compared to the aggregation rates arising from low $\mathrm{pH}$ alone $[9,10]$. Kulsing also experimented using lysozyme adsorbed to a chromatography column at different temperatures. Conformational changes upon elution where measured ex-situ using Small Angle X-ray Scattering (SAXS) which was connected to the column's outlet and showed that the protein was larger at higher concentrations. These conformational changes were also attributed to the 'on-column residency effects rather than just detecting a temperature-induced shift' [11].

The architecture of the media impacts desorption, adsorption, stability, retention and transport rates of the protein during the chromatographic process [12]. It is thus vital to not only characterise the architecture of the media, but also to understand its effect on protein behaviour within the material itself. However, this has proven to be challenging to characterise following traditional approaches. Imaging techniques, such as optical microscopy that can be used to visualise the macro and microstructure of these materials, lack the resolution required to reveal structural information. Methods with the required nanoscale resolution, such as atomic force microscopy and electron microscopy, often demand tailored sample preparation, for instance drying, and thus the output may not reflect the in situ conditions. Techniques like inverse size- 
exclusion chromatography (ISEC) that can measure surface area and pore distribution at these length scales do not provide information on the material's architecture [12]. Heigl et al. used MIR/NIR imaging to monitor the stationary phase compositions down to the low micrometer range of a polymer material. By using only one measurement, was able to determine the physicochemical characteristics about the chemical composition and the pore volume/area distributions[13]. However, there is still an opportunity for new characterisation techniques that not only measure the intrinsic structure of the media, but also the nanoscale distribution of the protein under the same conditions found during the chromatographic separation process. Therefore, novel techniques that can reveal the media's nanoscale structure, and the spatial distribution of the protein within the media, are needed, which will eventually benefit the design of new media as well as improve the modelling of existing ones [12]. The work presented here aims to help address these issues.

Neutron and x-ray scattering techniques are powerful, non-destructive probes for studying the structure and dynamics of materials on the nano to micron scale and from picoseconds upwards. Neutrons are particularly useful for hydrogenous/soft materials under processing conditions due to their high sensitivity to light elements, and hydrogen in particular, and to their high penetrating power allowing them to probe samples contained within a complex experimental apparatus, such as pressure cells and temperature regulators [14]. For example Mazzer et al. recently used Neutron Reflectivity to characterise the structure and orientation of adsorbed IgG on a model surface designed to mimic the affinity chromatography surface $[10,12]$. Moreover, neutron scattering power differs significantly between isotopes, allowing the judicial use of hydrogen/deuterium isotopic substitution to highlight one component in the presence of several others which are rendered invisible [15].

In the present work, we used Small Angle Neutron Scattering (SANS) to measure protein adsorption and the resulting resin bound protein structuring on the chromatographic media in a flow-through cell. Even though this technique is widely used by the scientific community, to the best of our knowledge, there are no previous studies on protein adsorption in chromatographic media using a flow through cell with SANS to study the chromatographic process. Pozzo used SANS to probe the conformation of SDS-BSA protein surfactant complexes during electrophoresis in cross-linked polyacrylamide gels [16]. This work demonstrated that SANS has the unique potential to probe nanoscale structures on complex systems that contain multiple components and that this technique is useful in understanding complex phenomena, such as polyelectrolyte electrophoretic migration in hydrogels[16]. In another study by Plewka et al., a flow cell was used during SAXS experiments when studying IgG adsorption on MabSelect Sure resin. The authors state that 'It was, therefore, possible for the first time to directly correlate the nanostructure changes inside the column, which is otherwise a black box, with the adsorption and elution process' [17]. As described by Koshari et al., SANS is very well suited for this application as it can resolve spatial features from the micrometre to the nanometre length scale. It can also characterise the static, as well as the dynamic aspects of the structure, without being disruptive to the sample $[12,18]$.

Here, we aim to establish SANS as a feasible characterisation technique to study protein adsorption in chromatographic media at the nanoscale to mesoscale. We also wish for the first time to perform these experiments under real-time affinity chromatography conditions using 
SANS. For this purpose, a custom-made quartz flow-through cell was built mimicking the affinity chromatography columns, and the IgG1 was adsorbed onto Prosep Ultra Plus resin (Figure 1).

\section{Materials and Methods}

\subsection{Materials}

For protein A chromatography, a silica-based resin (Prosep Ultra Plus, Millipore, Hertfordshire, UK) was used. The model protein for this study was IgG1, protein A purified humanised IgG1 produced in $\mathrm{CHO}$ cell culture, as described in El-Sabbahy et al.,[19]. It was dialysed into a running buffer (sodium phosphate, $\mathrm{pH} 7.2$ ) with a final concentration of $1 \mathrm{mg} / \mathrm{mL}$. For contrast matching experiments, the bare silica beads (Prosep Ultra Plus without the ligand) were kindly donated by Millipore. All buffer materials, sodium phosphate monobasic, sodium chloride, deuterium oxide at $99.8 \%$ atom D, sodium caprylate, urea, isopropanol, hydrochloric acid and sodium hydroxide were purchased from Sigma-Aldrich. Slide-A-Lyzer ${ }^{\circ} 10 \mathrm{~K}$ Dialysis Cassettes with molecular weight cut-off (MWCO) of 10000 and Spectrum Spectra/Por molecular porous membrane tubing of 12 to 14000 MWCO were from ThermoFisher Scientific.

\subsection{Equipment}

SANS measurements at the NIST Center for Neutron Research (NCNR), National Institute of Standards and Technology (NIST), Gaithersburg, MD, USA, were performed on a 30-meter-long Small Angle Neutron Scattering (SANS) instrument, NGB30. SANS experiments at ISIS Neutron and Muon Source, Science and Technology Facilities Council (STFC), Rutherford Appleton Laboratory (RAL), Didcot, UK were performed using the SANS2d instrument. Scanning electron microscopy was conducted using a JSM-6480LV, scanning electron microscope with a high resolution of 3.0 $\mathrm{nm}$ at University College London, UK.

\subsection{Methods}

\subsubsection{Sample preparation for SANS experiments}

IgG1 was prepared by overnight dialysis into $60.5 \% \mathrm{D}_{2} \mathrm{O}$ (the resin contrast match point was found in preliminary studies, as discussed in 2.3.3) based $0.03 \mathrm{~mol} / \mathrm{L}(\mathrm{M})$ sodium phosphate buffer, $\mathrm{pH}$ 7.2 using Slide-A-Lyzer ${ }^{\circ}$ 10K Dialysis Cassettes of 10000 MWCO and Spectrum Spectra/Por ${ }^{\circ}$ molecular porous membrane tubing of 12 to $14000 \mathrm{MWCO}$ (ThermoFisher Scientific). The resulting solutions were diluted to a concentration of $1 \mathrm{mg} / \mathrm{mL} \operatorname{lgG} 1$. The final concentration was determined by measuring the absorbance at $280 \mathrm{~nm}$ with a NanoDrop Spectrophotometer using Beer's law and an extinction coefficient of $\varepsilon_{280}^{0.1 \%} \mathrm{~nm}=1.4$ (experimentally determined by ThermoScientific, USA). Before injection into the flow-through cell, IgG1 was filtered through a $0.45 \mu \mathrm{m}$ membrane.

For the static experiments, the resin, initially in the company's (Millipore) solution, had undergone buffer exchange $\left(60.5 \% \mathrm{D}_{2} \mathrm{O}\right.$ - based $0.03 \mathrm{M}$ sodium phosphate buffer, $\left.\mathrm{pH} 7.2\right)$ in batches of $10 \mathrm{~mL}$. This was achieved by firstly centrifuging the resin for $2 \mathrm{~min}$. The excess liquid at the top was removed, and the tube was topped up to $10 \mathrm{~mL}$ with $0.03 \mathrm{M}$ sodium phosphate buffer. It was then incubated on a roller for $10 \mathrm{~min}$. The process was repeated three times. After the final centrifuge round the tube was topped up to $5 \mathrm{~mL}$, ready to be used for the column packing.

For the static bead characterisation studies, $0.9 \mathrm{~g}$ of bare silica beads, already in dry powder form, was dissolved in a $100 \% \mathrm{D}_{2} \mathrm{O}$ - based $0.03 \mathrm{M}$ sodium phosphate buffer, $\mathrm{pH}$ 7.2. The beads were packed in a demountable quartz window sample cell with a path length (thickness) of $1 \mathrm{~mm}$. 


\subsubsection{Flow through cell packing}

Firstly, the bottom filter, the outlet fittings and tubing of the column were fitted. The column was filled with $20 \%$ ethanol solution from the top, to remove all air. The diluted resin was gradually added into the column using a syringe until it was full and left overnight for the resin to settle using gravitational force. If needed, more resin was added to fill any empty gaps. Once full, the top filter and tubing of the column were fitted. Finally, the column was washed with either $20 \%$ ethanol or distilled water at a low flow rate $(0.01 \mathrm{~mL} / \mathrm{min})$ overnight to remove any air bubbles. The experimental buffer solution ( $0.03 \mathrm{M}$ sodium phosphate buffer, $\mathrm{pH} 7.2$ ) was pumped into the column prior to Small Angle Scattering measurements.

\subsubsection{Small-angle neutron scattering experiments}

Hydrogen isotopes play an essential role in neutron scattering when studying biological materials. Neutrons interact very differently in the presence of ${ }^{1} \mathrm{H}$ (protium) than when in the presence of ${ }^{2} \mathrm{H}$ (deuterium). This property is known as scattering length, with $\AA$ units. Protium has a negative scattering length $\left(-3.74 \times 10^{-5} \AA\right)$ whereas deuterium, on the other hand, has a very large scattering length $\left(6.67 \times 10^{-5} \AA\right)$ [20]. When characterising large structures or bulk materials like proteins, their scattering length density (SLD) is calculated by adding up the molecules' scattering lengths and then dividing by the total volume. Meaning that the scattering length density of $\mathrm{H}_{2} \mathrm{O}$ is negative $\left(-0.56 \times 10^{-6} \AA^{-2}\right)$ and that of $\mathrm{D}_{2} \mathrm{O}$ is positive $\left(6.35 \times 10^{-6} \AA^{-2}\right)$ [21]. By mixing $\mathrm{D}_{2} \mathrm{O}$ and $\mathrm{H}_{2} \mathrm{O}$, the SLD can be manipulated.

The fact that hydrogen is in high abundance in nature makes it easy to exploit this contrast creating property, by either suspending the sample in a $\mathrm{D}_{2} \mathrm{O}$-based mobile phase or by isotopically labelling the material of interest. These methods can create a high contrast between the suspension medium and the sample, or even between different subunits of a molecule [22].The components of the system are matched out based on the mixing of $\mathrm{H}_{2} \mathrm{O}$ and $\mathrm{D}_{2} \mathrm{O}$. Neutron scattering only occurs if the SLD of the particles differs from its bulk solution. Therefore, matching one system component out, enables researchers to work out the distribution of another.

In the present study, we wished to render the resin invisible (remove all resin scattering) by matching its SLD to that of the solution. By removing the resin scattering, the scattering from the resin bound protein was revealed. The contrast matching point of the bare silica beads (the base matrix) was reported being $60.5 \% \mathrm{D}_{2} \mathrm{O}$ by Dr Mazzer [23] . The experiment however, was repeated to confirm the data. The beads were suspended in different $\mathrm{H}_{2} \mathrm{O} / \mathrm{D}_{2} \mathrm{O}$ ratios and it was confirmed that the contrast matching point of this silica matrix was indeed at $60.5 \% \mathrm{D}_{2} \mathrm{O}$. Any further experiments were therefore carried out under contrast matching conditions. Agarose and cellulose based resins, are also of a great interest, since are the most common resins used in affinity chromatography separation processes. However, their characterisation using the contrast matching approach has been proven challenging due to the fact that agarose and cellulose based matrices have very similar contrast matching points to the protein molecules $\left(38 \% D_{2} O\right)$, thus rendering both the resin and the protein of interest invisible.

In summary, Small-Angle Neutron Scattering arises from variations in the scattering length density, which generally reflects structural heterogeneities in the sample. The intensity of scattered neutrons is recorded as a function of the angle, $\theta$, from the incident beam at any given wavelength, $\lambda$. These counts are recorded as a function of $Q$, the scattering vector, also known as the momentum transfer vector, which is defined as:

$$
Q=4 \pi / \lambda * \sin \theta / 2
$$

Eq. 1

Where $\lambda$ is the neutron wavelength. $Q$ thus has units of inverse length (usually $\AA^{-1}$ ) and the data collected as a function of $Q, I(Q)$, is said to be in reciprocal space [18]. This measured intensity 
provides insights about the structure of the sample. $Q$ and the length scale being probed, $L$, are directly related by Bragg's law [18],

$L=2 \pi / Q$

Eq. 2

Therefore, the real-space structures in the sample are inversely related to the features observed in the SANS profile.

At the NCNR each sample was measured with a fixed wavelength of $6 \AA$, using a $2 \times 1 \mathrm{~cm}$ beam size, at three diffractometer settings, a high $\mathrm{Q}-1 \mathrm{~m}$ sample to detector distance (SDD), an intermediate $Q-4 \mathrm{~m} \mathrm{SDD}$, and a low $Q-13 \mathrm{~m}$ SDD. In some cases, an extra setting, using an 8.4 $\AA$ wavelength and a $13 \mathrm{~m}$ SDD with lenses, was used to reach very low $Q$. The resulting maximum scattering range was $0.001 \AA^{-1}<Q<0.4 \AA^{-1}$ with a wavelength spread, $\Delta \lambda / \lambda$, of 0.15 . At ISIS, a 10 $\mathrm{Hz}$ pulsed neutron source, a time-of-flight Small Angle Neutron Scattering instrument was used with a beam size of $6 \mathrm{~mm}$ in diameter, utilising a $2 \AA$ to $14 \AA$ Aavelength band. The sample-detector distance was also varied from $2 \mathrm{~m}$ to $12 \mathrm{~m}$ to achieve a total scattering range of $0.004 \AA^{-1}<\mathrm{Q}<$ $1.77 \AA^{-1}$. All experiments were performed at room temperature.

The column was placed on the sample stage and connected to an Aladdin syringe pump (NCNR) or a Knauer HPLC pump (ISIS), with valved tubing to avoid any air contamination during the buffer changes and IgG loading. The antibody solution was gradually added into the system at a flow rate of $1 \mathrm{~mL} / \mathrm{min}$ until the desired concentration was reached $(10 \mathrm{mg}, 30 \mathrm{mg}, 50 \mathrm{mg})$. The antibody was incubated for $10 \mathrm{~min}$ and then washed by flowing buffer through it to remove any unbound molecules. The beam was directed towards the top area of the column to get a representative understanding of protein adsorption behaviour within particulate resin. For each concentration, measurements were taken under two different washing buffer conditions, $0.03 \mathrm{M}$ sodium phosphate, $\mathrm{pH} 7.2$ and $0.03 \mathrm{M}$ sodium phosphate with $1 \mathrm{M}$ urea and $10 \%$ of the total volume isopropanol, $\mathrm{pH} 8$, resulting in 2 data sets for each concentration yielding a total of 6 data sets.

\subsubsection{Data reduction}

To obtain the corrected and radially averaged SANS scattering spectra for the NIST data, Igor Pro was used with the NCNR provide macros [24], and standard data reduction procedures were followed, whereas, for the ISIS data reduction, the reduction program, Mantid was employed [25]. In this case, the contrast matched resin in buffer SANS profile was used to subtract the background from the experimental data sets. Igor Pro was then used to obtain the averaged SANS spectra plots. ISIS raw data will be publicly available to download upon request in 2021 using the experiment's DOI, 10.5286/ISIS.E.95670476 [26].

\subsubsection{Modelling}

A broad peak model was selected to fit the collected data using the SasView modelling software [27]. In this model the broad scattering peak from SANS data is represented by an empirical functional form calculated by [28]:

$I(Q)=\mathrm{A} / Q^{n}+\mathrm{C} /\left(\left|Q-Q_{0}\right| \xi\right)^{m}+B$

Eq. 3

Where $\mathrm{A}$ and $\mathrm{C}$ are scaling factors, $\mathrm{n}$ is the Porod law exponent, $\mathrm{m}$ and $\xi$ are the Lorentz exponent and screening length respectively and the peak position, $Q_{0}$, is related to the $d$-spacing in the system as given in eq. 3 . This basic model was used to translate the observed scattering peaks into real correlation lengths. 


\subsubsection{SEM}

Bare silica beads (no ligand) were investigated using an SEM to visualise the inner structure of the resin. Beads were in a powder form already, thus eliminating the need for prior drying. The beads were placed on aluminium slabs and were sputter-coated with a gold layer. For the visualisation, multiple magnifications were used, from $\times 250$ to $\times 100,000$, which corresponds to length scales of $100 \mu \mathrm{m}$ to $0.1 \mu \mathrm{m}$. SEM images were analysed by the ImageJ software [29] to obtain the average pore size as well as the average pore-to-pore correlation distance.

\section{Results and discussion}

\subsection{Characterisation of bare silica beads}

To obtain an internal structure overview of the bare silica beads (Prosep Ultra Plus resin beads before protein A coating) and characterise their pore size distribution, an SEM was utilised. The same beads were also examined via SANS, allowing for in situ structural characterisation of the chromatography resin. Since scattering measurements are performed in Fourier, or reciprocal, space ([30] whereas microscopy techniques are performed in real space (real world coordinates), the SEM images underwent Fourier Transformation (FT) in order to be able to compare the scattering and SEM data in the same reciprocal space. The FT-SEM image and the SANS profile exhibited a notable similarity, as expected. It was noted that both contained one broad peak at low scattering vector $(Q) \AA^{-1}$ and one less distinct peak at mid $Q$. The two features are likely to be broad peaks related to the resin's pore-to-pore correlation distance, first peak, and the pore size correlation, second peak (Figure 2). The fact that the peak is broad indicates that there is a range of pore sizes in the resin. The manufacturing specification states an average pore size of $70 \mathrm{~nm}$ (Millipore, 2014). The silica average pore size obtained from SANS was approximately $63 \mathrm{~nm}$ and $66 \mathrm{~nm}$ from the FT-SEM.

\subsection{Structural characterisation of resin-bound protein}

Prosep Ultra Plus specifications state that the dynamic binding capacity of the resin is $\approx 50$ $\mathrm{mg} / \mathrm{mL}$ and this value was confirmed by performing a resin breakthrough experiment on an AKTA prior to the SANS experiments (data not shown as this is beyond the scope of this paper). Note that in some cases the resin was loaded beyond its binding capacity (e.g. $69 \mathrm{mg} / \mathrm{mL}$ and beyond) in order to ensure resin saturation of the protein $A$ binding sites inside the column during the SANS experiment.

Under contrast matching conditions, any observed scattering was solely due to the protein molecules in the system. However, there were two types of protein in the system, protein A ligand and IgG molecules. With the contrast matching approach, the resin could not be perfectly matched out due to the presence of bound protein $A$ on the resin surface. Yet, the fact that the protein $A$ distribution on the resin surface in-situ can be seen once the resin beads are matched out, is by itself novel and should be highlighted. This method opens the door to new ways of investigating ligands attached on affinity chromatography resins in-situ and consequently to their improvement.

Before injecting IgG into the column (Figure 4- Blue line), any measured scattering was due to the protein A ligand attached to the silica beads' surface. The scattering profile contained one broad peak, visible at a low $Q\left(0.0047 \AA^{-1}\right)$, which correlates to a spacing of $133 \mathrm{~nm}$, reminiscent of the pore-to-pore correlation distance, suggesting protein $A$ decoration of the resin surface, as expected. 
After loading the column (up to $69 \mathrm{mg} / \mathrm{mL}$ IgG: Figure 4-purple line), there were two peaks visible in the lower $Q$ range data $\left(0.001-0.5 \AA^{-1}\right)$. The first peak that corresponded to the pore to pore correlation of the silica beads, $133 \mathrm{~nm}\left(0.0047 \AA^{-1}\right)$, and a second peak centred at $0.01 \AA^{-1}$, which translates to $D=63 \mathrm{~nm}$. The second peak is attributed to the pore size observed in the resin data. These findings correspond well to the SEM images of the bare silica beads obtained previously (Figure 2).

Measuring the system at the higher $Q$ range $\left(0.005-1.2 \AA^{-1}\right)$, enabling the examination of smaller length scales approaching the IgG molecular size, allowed us to observe the interactions between the individual IgG molecules and the resin surface. Figure 5 shows the measurements taken after the addition of $30 \mathrm{mg} \lg \mathrm{G}$ into the system. An additional peak was observed at an even higher $\mathrm{Q}$ of $0.1 \AA^{-1}$ corresponding to a repeat distance of $4.2 \mathrm{~nm}$. Our interpretation is that this feature was IgG related, since it only appeared after the addition of IgG molecules in the column and the resin and water are matched, meaning the scattering is only sensitive to protein structure. Based on the size of the IgG molecule, and previous reflectivity data [10] which suggested the densest bound protein region was close to the resin/water interface, we deduced that this peak corresponds to the repeat distance between IgG molecules bound onto the protein $A$ surface.

\subsection{Protein A - IgG binding}

Protein A binding takes place at the $\mathrm{Fc}$ region of the $\mathrm{IgG}$, between the $\mathrm{CH} 2$ and $\mathrm{CH} 3$ domains. Native Staphylococcus aureus protein $A$ is a tetramer that, when stretched, has an approximate length of $10 \mathrm{~nm}$, and a single domain length of $\sim 3 \mathrm{~nm}$ (Protein Data Bank:1BDD [31]). Mazzer et al. and Silva et al. suggested the binding is usually at a 2:1 ratio [10,32] when used as an affinity chromatography ligand, whereas Plewka et al. [17] estimated that antibodies bind to protein A molecules at a 1.2:1 ratio. They both agree however that the $\lg G$ molecules are bound to the protein A ligand at a tilted orientation near the resin surface $[10,17]$. Since the Fc regions of the IgG molecules are adsorbed onto protein $A$ and stacked next to each other, they can be thought of as having little flexibility, thus making a dense protein layer. The Fab regions extended away from the surface, however, retaining extensive flexibility and making them a much less dense layer, with less order (no repeated distances). The system layers are described in more detail by Mazzer et al. [10] who used neutron reflectivity where such data can be obtained using an idealised environment, with protein A ligands immobilised on silicon wafers instead of on native chromatography resins. In summary, they propose that during adsorption of the IgG, there are two distinct layers, an inner protein and an outer protein layer with volume fractions of 0.4 and 0.05 respectively. The inner layer consists of a densely packed Fc domains, whereas the outer layer contains the Fab arms extending outwards, forming a more sparse protein layer [10]. Based on crystallographic and SAXS data of IgG molecules, a maximum distance of $15 \mathrm{~nm}$, a Fab distance of $7 \mathrm{~nm}$ and an Fc region distance of roughly $5 \mathrm{~nm}[33,34]$ is assumed, our SANS findings also suggest a very closely packed layer near the surface, since the average distance between the molecules is $4.2 \mathrm{~nm}$. For the IgGs to arrange themselves in such close proximity, the IgG molecules should be stack side by side at a 90 degree rotation, with their Fab domains extending outwards. It should be noted however, that this was a broad peak and around four orders of magnitude less than the other two peaks at the lower $\mathrm{Q}$. This suggests that there is a loose correlation between antibody molecules and that the distances could vary significantly. Deisenhofen also used crystallography at a resolution of $2.9 \AA$ and $2.8 \AA$ to measure the $B$ domain of the protein $A$, the Fc-binding domain, in complex with the IgG FC fragment. They recorded an increased $\mathrm{C}_{\mathrm{H}} 2$ disorder when the $\mathrm{FC}$ fragment was bound to the protein A compared to the unbound Fc fragment, which suggests a potential Fc destabilization during protein $\mathrm{A}$ adsorption [5]. 


\subsection{Characterisation of the solid/liquid interface under typical chromatographic conditions}

SANS measurements performed at the high $Q$ range, focusing on the $\lg G$ molecular scale, were taken at several IgG concentrations $(10 \mathrm{mg} / \mathrm{mL}, 30 \mathrm{mg} / \mathrm{mL}$ and $50 \mathrm{mg} / \mathrm{mL}$ ) adsorbed to the protein A resin under normal chromatographic conditions ( $0.03 \mathrm{M}$ sodium phosphate, $\mathrm{pH} 7.2)$. As seen in Figure 6, all three concentrations showed an IgG correlation peak at the high $Q(\approx 0.1 \AA)$. As indicated previously, the $D$ spacing of this peak was approximately $4.2 \mathrm{~nm}$ and represents the inplane distance between the IgG molecules at the most densely packed protein layer. The peak was fit to a Broad peak model, as discussed in the methods section. Antibody adsorption into the protein A resins follows a shrinking core behaviour [35] meaning that as the antibody concentration increases, the IgG molecules start to progressively occupy the resin surface from the outside and moving towards the centre of the bead. At higher concentrations, IgG molecules occupy any empty spaces left. However, as the concentration increases, IgG molecules have poor stability and a tendency to form aggregates and thus the layer becomes less ordered, which could address the fact that the $50 \mathrm{mg} / \mathrm{mL}$ peak is slightly broader than the previous one[36].

\subsection{Urea buffer effect on the solid/liquid interface}

In the final study, the buffer was changed to $0.03 \mathrm{M}$ sodium phosphate plus $1 \mathrm{M}$ of urea and $10 \%$ of the total volume isopropanol based buffer, $\mathrm{pH} 8$, to mimic what can be used as a wash buffer in order to remove non-specifically bound impurities derived from the clarified cell culture supernatant. As a result, the peak located at the high $Q$ region that previously corresponded to the protein clusters correlation peak, was no longer visible in any of the three concentrations (Figure 7). At first, it could be assumed that the urea buffer disrupted the protein A - IgG binding and removed the IgG molecules from the system altogether. When examining the system at the lower $Q$ range under the same conditions, however, both pore-to-pore and pore-size correlation peaks were still present (Figure 8), which meant that the IgG molecules were still present, decorating the resin surface. These findings disprove our initial hypothesis. Instead, the absence of a visible protein peak indicates the buffer had disrupted the order of the system (no strong repeat distances) suggesting the urea buffer has had a destabilising effect on the protein clusters, causing partial unfolding of the antibody molecules. This has been observed in other related systems where harsher buffers caused partial unfolding and loss of native protein structure $[37,38]$. Urea at high concentrations, for example, $4 \mathrm{M}$, acts as a chaotrope and is known to have a destabilising effect on proteins via both direct and indirect mechanisms [39]. As discussed by Bennion. et al., 2003, urea interacts directly with the peptide groups present in the protein and forms hydrogen bonds [39]. However, at low concentrations such as the $1 \mathrm{M}$ used in this study, urea is often used as an additive in the washing buffer to remove any non-specifically bound impurities without, it is assumed, disturbing the protein A - IgG attachment. Furthermore, isopropanol is an organic solvent that mitigates solvophobic interactions. During a study by Shukla et al., they found that adding a combination of $1 \mathrm{M}$ urea and $10 \%$ of the total volume isopropanol to the washing buffer, successfully removed a significant percentage of the impurities present. They showed that this was true for several Fc fusion proteins and monoclonal antibodies. This widely applicable wash condition can eradicate the need for a product-specific optimisation of wash conditions [40]. Here we show that this buffer system is disordering the bound antibody structure, this could be the basis for the desorption of antibody bound host cell protein impurities described by [40]. It also raises questions about antibody stability during such wash conditions, however following elution recovery of antibody's conformational state as seen in [11] albeit for a different system is expected. 


\section{Conclusions}

Small Angle Neutron Scattering was performed with a custom-made flow-through cell designed to replicate typical protein $A$ affinity chromatography conditions. All initial experiments were performed under typical chromatographic conditions with $0.03 \mathrm{M}$ sodium phosphate, $\mathrm{pH} 7.2$, as the washing buffer. Under off-contrast matching conditions $\left(100 \% \mathrm{D}_{2} \mathrm{O}\right)$, the bare silica beads appear to give two distinct correlation peaks arising from pore-to-pore and pore size correlations respectively. The contrast matching point of silica was measured to be $60.5 \% \mathrm{D}_{2} \mathrm{O}$, at which it renders the Prosep Ultra Plus resin beads invisible to neutrons and enables the investigation of only the protein molecules in the system, protein $A$ and antibody molecules. All subsequent experiments were performed under these contrast matching conditions. Protein A had a very weak scattering signal and therefore, any observed excess scattering was attributed to the antibody molecules. Once the antibody molecules were added into the column, two correlation peaks appeared at the lower $Q$ range (pore-to-pore and pore size), just as in the bare silica case, indicating that the antibodies adsorbed to the surface of the resin. A third peak was also detectable at the high $Q$ range arising from the in-plane distance between the IgG clusters and was concentration-dependent indicating increased ordering accompanying the increased packing from the increased loading. The system was finally examined under a different washing buffer, $0.03 \mathrm{M}$ sodium phosphate with $1 \mathrm{M}$ urea and $10 \%$ of the total volume isopropanol at $\mathrm{pH} 8$ which caused the disappearance of the high $Q$ peak. This suggested that the urea disrupted the system's order by causing partial unfolding of the adsorbed antibody molecules, thereby causing a loss of order on the surface. However, the molecules were still decorating the resin's surface, so the pore-to-pore and pore size correlation peaks remained visible indicating the protein remained bound. In summary, the washing procedure seems to cause a disruption to these tightly packed proteins which could be a contributing factor to some of the increase in aggregation observed after passing through a column. The technique provides a unique way to investigate the nanoscale structure of chromatography resin and behaviour of the adsorbed protein within the media under different conditions. These findings will be beneficial when designing new chromatographic media, as well as improving upon the modelling of existing ones.

\section{Acknowledgements}

This work was supported by the UK Engineering and Physical Sciences Research Council (EPSRC) Centre for Doctoral Training in Emergent Macromolecular Therapies: A National CDT linked to an EPSRC Centre for Innovative Manufacturing, grant EP/L015218/1). We also acknowledge the support of the ISIS, Rutherford Appleton Laboratory, Harwell Science and Innovation Campus, UK, in providing the neutron research facilities used in this work (ISIS beamtime awards RB1810228), and the U.S. National Institute of Standards and Technology (NIST 70NANB12H239), for access to the NGB30 SANS instrument provided by the Center for High Resolution Neutron Scattering, a partnership between the National Institute of Standards and Technology and the National Science Foundation under Agreement No. DMR-1508249. The donation of bare silica beads by Millipore is gratefully acknowledged. Certain commercial equipment, instruments, or materials (or suppliers, or software, ...) are identified in this paper to foster understanding. Such identification does not imply recommendation or endorsement by the National Institute of Standards and Technology, nor does it imply that the materials or equipment identified are necessarily the best available for the purpose. This work benefited from the use of the SasView application, originally developed under NSF Award DMR-0520547. SasView also contains code developed with funding from the EU 
Horizon 2020 programme under the SINE2020 project Grant No 654000. Finally, unless otherwise stated, all uncertainties represent one standard deviation. ISIS raw data will be publicly available to download upon request in 2021 using the experiment's DOI, 10.5286/ISIS.E.95670476 [26].

\section{References}

[1] A.L. Fink, Protein aggregation: Folding aggregates, inclusion bodies and amyloid, Fold. Des. 3 (1998) 9-23. doi:10.1016/S1359-0278(98)00002-9.

[2] O.B. Ptitsyn, Structures of folding intermediates, Curr. Opin. Struct. Biol. 5 (1995) 74-78. doi:10.1016/0959-440X(95)80011-0.

[3] R.F. Latypov, S. Hogan, H. Lau, H. Gadgil, D. Liu, Elucidation of acid-induced unfolding and aggregation of human immunoglobulin IgG1 and IgG2 Fc, J. Biol. Chem. 287 (2012) 1381-1396. doi:10.1074/jbc.M111.297697.

[4] E. Lopez, N.E. Scott, B.D. Wines, P.M. Hogarth, A.K. Wheatley, S.J. Kent, A.W. Chung, Low pH Exposure During Immunoglobulin G Purification Methods Results in Aggregates That Avidly Bind Fcy Receptors: Implications for Measuring Fc Dependent Antibody Functions, Front. Immunol. 10 (2019) 1-15. doi:10.3389/fimmu.2019.02415.

[5] J. Deisenhofer, Crystallographic refinement and atomic models of a human Fc fragment and its complex with fragment B of protein A from Staphylococcus aureus at 2.9- and 2.8-.ANG. resolution, Biochemistry. 20 (1981) 2361-2370. doi:10.1021/bi00512a001.

[6] J. Deisenhofer, T.A. Jones, R. Huber, J. Sjödahl, J. Sjöquist, Crystallization, crystal structure analysis and atomic model of the complex formed by a human Fc fragment and fragment B of protein A from Staphylococcus aureus., Hoppe. Seylers. Z. Physiol. Chem. 359 (1978) 975-85. doi:10.1515/bchm2.1978.359.2.975.

[7] P. Gagnon, R. Nian, D. Leong, A. Hoi, Transient conformational modification of immunoglobulin G during purification by protein A affinity chromatography, J. Chromatogr. A. 1395 (2015) 136-142. doi:10.1016/J.CHROMA.2015.03.080.

[8] P. Gagnon, R. Nian, Conformational plasticity of IgG during protein A affinity chromatography, J. Chromatogr. A. 1433 (2016) 98-105. doi:10.1016/J.CHROMA.2016.01.022.

[9] A.A. Shukla, P. Gupta, X. Han, Protein aggregation kinetics during Protein A chromatography: Case study for an Fc fusion protein, J. Chromatogr. A. 1171 (2007) 22-28. doi:10.1016/J.CHROMA.2007.09.040.

[10] A.R. Mazzer, L.A. Clifton, T. Perevozchikova, P.D. Butler, C.J. Roberts, D.G. Bracewell, Neutron reflectivity measurement of protein $\mathrm{A}$-antibody complex at the solid-liquid interface, J. Chromatogr. A. 1499 (2017) 118-131. doi:10.1016/J.CHROMA.2017.03.084.

[11] C. Kulsing, A.Z. Komaromy, R.I. Boysen, M.T.W. Hearn, On-line determination by small angle X-ray scattering of the shape of hen egg white lysozyme immediately following elution from a hydrophobic interaction chromatography column, Analyst. 141 (2016) 5810-5814. doi:10.1039/c6an00851h.

[12] S.H.S. Koshari, N.J. Wagner, A.M. Lenhoff, Characterization of lysozyme adsorption in cellulosic chromatographic materials using small-angle neutron scattering, J. Chromatogr. A. 1399 (2015) 45-52. doi:10.1016/J.CHROMA.2015.04.042. 
[13] N. Heigl, A. Greiderer, C.H. Petter, O. Kolomiets, H.W. Siesler, M. Ulbricht, G.K. Bonn, C.W. Huck, Simultaneous Determination of the Micro-, Meso-, and Macropore Size Fractions of Porous Polymers by a Combined Use of Fourier Transform Near-Infrared Diffuse Reflection Spectroscopy and Multivariate Techniques, Anal. Chem. 80 (2008) 8493-8500. doi:10.1021/ac8013059.

[14] P.S. Singh, Small-Angle Scattering Techniques (SAXS/SANS), Membr. Charact. (2017) 95-111. doi:10.1016/B978-0-444-63776-5.00006-1.

[15] L.A. Clifton, S.C.L. Hall, N. Mahmoudi, T.J. Knowles, F. Heinrich, J.H. Lakey, Structural Investigations of Protein-Lipid Complexes Using Neutron Scattering, 2019. doi:10.1007/978-14939-9512-7_11.

[16] D.C. Pozzo, Neutron-scattering probe of complexes of sodium dodecyl sulfate and serum albumin during polyacrylamide gel electrophoresis, Langmuir. 25 (2009) 1558-1565. doi:10.1021/la8039994.

[17] J. Plewka, G.L. Silva, R. Tscheließnig, H. Rennhofer, C. Dias-Cabral, A. Jungbauer, H.C. Lichtenegger, Antibody adsorption in protein-A affinity chromatography - in situ measurement of nanoscale structure by small-angle X-ray scattering, J. Sep. Sci. 41 (2018) 4122-4132. doi:10.1002/jssc.201800776.

[18] S.H.S. Koshari, N.J. Wagner, A.M. Lenhoff, Effects of Resin Architecture and Protein Size on Nanoscale Protein Distribution in Ion-Exchange Media, Langmuir. 34 (2018) 673-684. doi:10.1021/acs.langmuir.7b03289.

[19] H. El-Sabbahy, D. Ward, O. Ogonah, L. Deakin, G.M. Jellum, D.G. Bracewell, The effect of feed quality due to clarification strategy on the design and performance of protein A periodic countercurrent chromatography, Biotechnol. Prog. 34 (2018) 1380-1392. doi:10.1002/btpr.2709.

[20] T.J. Su, J.R. Lu, R.K. Thomas, Z.F. Cui, J. Penfold, The Adsorption of Lysozyme at the Silica-Water Interface: A Neutron Reflection Study, J. Colloid Interface Sci. 203 (1998) 419-429. doi:10.1006/JCIS.1998.5545.

[21] R. Pynn, Neutron Applications in Earth, Energy and Environmental Sciences, (2009) 1-29. doi:10.1007/978-0-387-09416-8.

[22] L.A. Clifton, C. Neylon, J.H. Lakey, Lipid-Protein Interactions, 2013. doi:10.1007/978-1-62703-2759.

[23] A.R. Mazzer, Understanding the Influence of Adsorption-Mediated Processes on Antibody Aggregation in Bioprocessing Doctor of Philosophy in Biochemical Engineering, 2015.

[24] S.R. Kline, Reduction and analysis of SANS and USANS data using IGOR Pro, J. Appl. Crystallogr. 39 (2006) 895-900. doi:10.1107/S0021889806035059.

[25] O. Arnold, J.C. Bilheux, J.M. Borreguero, A. Buts, S.I. Campbell, L. Chapon, M. Doucet, N. Draper, R. Ferraz Leal, M.A. Gigg, V.E. Lynch, A. Markvardsen, D.J. Mikkelson, R.L. Mikkelson, R. Miller, K. Palmen, P. Parker, G. Passos, T.G. Perring, P.F. Peterson, S. Ren, M.A. Reuter, A.T. Savici, J.W. Taylor, R.J. Taylor, R. Tolchenov, W. Zhou, J. Zikovsky, Mantid - Data analysis and visualization package for neutron scattering and $\mu$ SR experiments, Nucl. Instruments Methods Phys. Res. Sect. A Accel. Spectrometers, Detect. Assoc. Equip. 764 (2014) 156-166. doi:10.1016/j.nima.2014.07.029.

[26] ISIS Data Home | Science \& Technology Facilities Council | STFC, (n.d.). https://data.isis.stfc.ac.uk/doi/STUDY/103196493/ (accessed December 30, 2019).

[27] M. Doucet, J.H. Cho, G. Alina, J. Bakker, W. Bouwman, P. Butler, K. Campbell, M. Gonzales, R. 
Heenan, A. Jackson, P. Juhas, S. King, P. Kienzle, J. Krzywon, A. Markvardsen, T. Nielsen, L. O’Driscoll, W. Potrzebowski, R. Ferraz Leal, T. Richter, P. Rozycko, T. Snow, A. Washington, SasView version 4.2, (2018). doi:10.5281/ZENODO.1412041.

[28] B. Hammouda, A new Guinier-Porod model, J. Appl. Crystallogr. 43 (2010) 716-719. doi:10.1107/S0021889810015773.

[29] C.A. Schneider, W.S. Rasband, K.W. Eliceiri, NIH Image to ImageJ: 25 years of image analysis., Nat. Methods. 9 (2012) 671-5. http://www.ncbi.nlm.nih.gov/pubmed/22930834 (accessed October 13, 2019).

[30] D. Mettus, A. Michels, Small-angle neutron scattering correlation functions of bulk magnetic materials, J. Appl. Crystallogr. 48 (2015) 1437-1450. doi:10.1107/S1600576715013187.

[31] H. Gouda, H. Torigoe, Y. Arata, I. Shimada, A. Saito, M. Sato, Three-Dimensional Solution Structure of the B Domain of Staphylococcal Protein A: Comparisons of the Solution and Crystal Structures, Biochemistry. (1992). doi:10.1021/bi00155a020.

[32] G. L. Silva, J. Plewka, H. Lichtenegger, A.C. Dias-Cabral, A. Jungbauer, R. Tscheließnig, The pearl necklace model in protein A chromatography: Molecular mechanisms at the resin interface, Biotechnol. Bioeng. 116 (2019) 76-86. doi:10.1002/bit.26843.

[33] J.S. Klein, P.N.P. Gnanapragasam, R.P. Galimidi, C.P. Foglesong, A.P. West, P.J. Bjorkman, Examination of the contributions of size and avidity to the neutralization mechanisms of the antiHIV antibodies b12 and 4E10, Proc. Natl. Acad. Sci. 106 (2009) 7385-7390. doi:10.1073/PNAS.0811427106.

[34] Y. Abe, J. Gor, D.G. Bracewell, S.J. Perkins, P.A. Dalby, Masking of the Fc region in human IgG4 by constrained $\mathrm{X}$-ray scattering modelling: Implications for antibody function and therapy, Biochem. J. 432 (2010) 101-111. doi:10.1042/BJ20100641.

[35] T.E. Bankston, M.C. Stone, G. Carta, Theory and applications of refractive index-based optical microscopy to measure protein mass transfer in spherical adsorbent particles, J. Chromatogr. A. 1188 (2008) 242-254. doi:10.1016/J.CHROMA.2008.02.076.

[36] D. Lowe, K. Dudgeon, R. Rouet, P. Schofield, L. Jermutus, D. Christ, Aggregation, stability, and formulation of human antibody therapeutics, Adv. Protein Chem. Struct. Biol. 84 (2011) 41-61. doi:10.1016/B978-0-12-386483-3.00004-5.

[37] W. Jin, Z. Xing, Y. Song, C. Huang, X. Xu, S. Ghose, Z.J. Li, Protein aggregation and mitigation strategy in low pH viral inactivation for monoclonal antibody purification., MAbs. (2019). doi:10.1080/19420862.2019.1658493.

[38] N. Codina, D. Hilton, C. Zhang, N. Chakroun, S.S. Ahmad, S.J. Perkins, P.A. Dalby, An Expanded Conformation of an Antibody Fab Region by X-Ray Scattering, Molecular Dynamics, and smFRET Identifies an Aggregation Mechanism, J. Mol. Biol. 431 (2019) 1409-1425. doi:10.1016/j.jmb.2019.02.009.

[39] B.J. Bennion, V. Daggett, The molecular basis for the chemical denaturation of proteins by urea, Proc. Natl. Acad. Sci. 100 (2003) 5142-5147. doi:10.1073/pnas.0930122100.

[40] A.A. Shukla, P. Hinckley, Host cell protein clearance during protein a chromatography: Development of an improved column wash step, Biotechnol Prog. 24 (2008) 1115-1121. doi:10.1021/bp.50. 
Figure captions:

Figure 1: Custom-made quartz flow through cell diagram

Custom-made quartz flow through cell made by the Sample Environment team at ISIS, RAL. Inlet and outlet are situated at the top and bottom of the cell respectively. The $1 \mathrm{~mL}$ chamber $(50 \mathrm{~mm} \times 8 \mathrm{~mm} \times 1$ $\mathrm{mm}$ ) in the middle of the cell is packed with resin. The neutron beam is fired perpendicularly to the cell. Neutrons penetrate it and are scattered to the detector. Measurements were performed at the top position of the cell, where the antibody concentration is the most accurate, since the antibody concentration differs across the column. This column is built to closely resemble the real life chromatographic columns.

Figure 2: Comparison between the SANS and FT data

A. Shows the SANS measurements of the bare silica beads at $100 \%$ D2O buffer composition (top blue line) and Fourier Transform from the SEM image of the dry bare silica beads (bottom red line). The circles indicate the peak locations. B. Shows the SEM image of the dry bare silica beads at an $\times 100,000$ magnification. The pore-to-pore correlation (pore centre-to- pore centre distance) is also shown along with the pore size. Error bars have been removed for clarity but are commensurate with the scatter in the data.

\section{Figure 3: Length scales involved in the affinity chromatography}

Length scales involved in the affinity chromatography. A. SEM of an individual silica bead with size 60 $\mu \mathrm{m}, \mathrm{B}$. Close-up of the silica bead surface showing the pores of an average size of $70 \mathrm{~nm}, \mathrm{C}$. Single silica bead pore coated with protein A (orange circles) and adsorbed IgG molecules with an average of $4.2 \mathrm{~nm}$ distance between them, D. Average distance between Fc regions of the IgG molecules. Figure not to scale.

Figure 4: Low $Q$ data and corresponding SEM features

The experimental data gathered from the low $Q$ regime. The blue line represents the system with no IgG present, displaying only one peak at $0.0048 \AA$. The purple line shows the data after the addition of $69 \mathrm{mg}$ of IgG into the system, which gives rise to two peaks at $0.0047 \AA$ and $0.01 \AA$ ( $133 \mathrm{~nm}$ and $63 \mathrm{~nm}$ in real space respectively). The SEM image on top of the data shows the pore size and pore to pore correlation respectively which give rise to the scattering peaks.

\section{Figure 5: High Q data and corresponding features}

The experimental data gathered from the high Q regime taken after the addition of $50 \mathrm{mg}$ of IgG into the cell. At $0.1 \AA(4.2 \mathrm{~nm})$ an additional peak is visible. At the top, is an IgG molecule schematic, showing what the $4.2 \mathrm{~nm}$ corresponds to, an in-plane repeat distance of IgG bound onto the resin surface.

Figure 6: High Q measurements at $10 \mathrm{mg} / \mathrm{mL}, \mathbf{3 0 ~ m g / m L}$ and $50 \mathrm{mg} / \mathrm{mL}$ of $\mathrm{IgG}$ under normal chromatographic conditions

SANS measurements (at the high $\mathrm{Q}$ ) were taken at increasing concentrations of $\operatorname{lgG}(10 \mathrm{mg} / \mathrm{mL}, 30$ $\mathrm{mg} / \mathrm{mL}$ and $50 \mathrm{mg} / \mathrm{mL}$ ) into the system under normal chromatographic conditions, $0.03 \mathrm{M}$ sodium phosphate, $\mathrm{pH} 7.2$. 
Figure 7: High Q measurements at $10 \mathrm{mg} / \mathrm{mL}, 30 \mathrm{mg} / \mathrm{mL}$ and $50 \mathrm{mg} / \mathrm{mL}$ of $\operatorname{lgG}$ under different washing buffer conditions

SANS measurements (at the high Q) were taken at increasing concentrations of $\operatorname{lgG}(10 \mathrm{mg} / \mathrm{mL}, 30$ $\mathrm{mg} / \mathrm{mL}$ and $50 \mathrm{mg} / \mathrm{mL}$ ) into the system in two different washing buffers, $0.03 \mathrm{M}$ sodium phosphate $\mathrm{pH}$ 7.2 and $1 \mathrm{M}$ urea and $10 \%$ of the total volume isopropanol in sodium phosphate, $\mathrm{pH} 8$.

Figure 8: Low $Q$ data when urea is added in the washing buffer

SANS measurements (at the lower $\mathrm{Q}$ ) of adsorbed antibody molecules in $0.03 \mathrm{M}$ sodium phosphate plus $1 \mathrm{M}$ urea and $10 \%$ of the total volume isopropanol, $\mathrm{pH} 8$. 
Figure 1

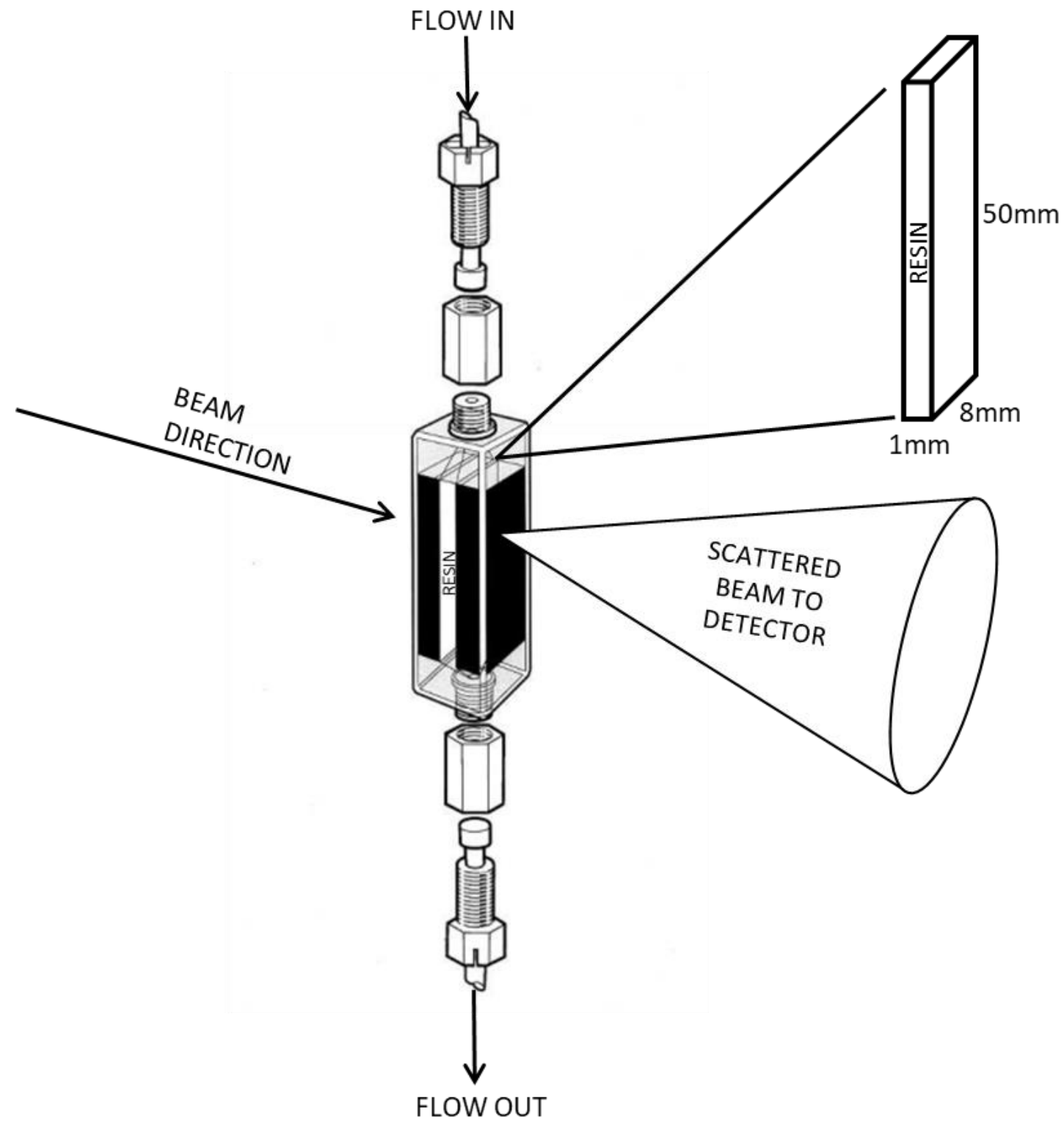


Figure 2

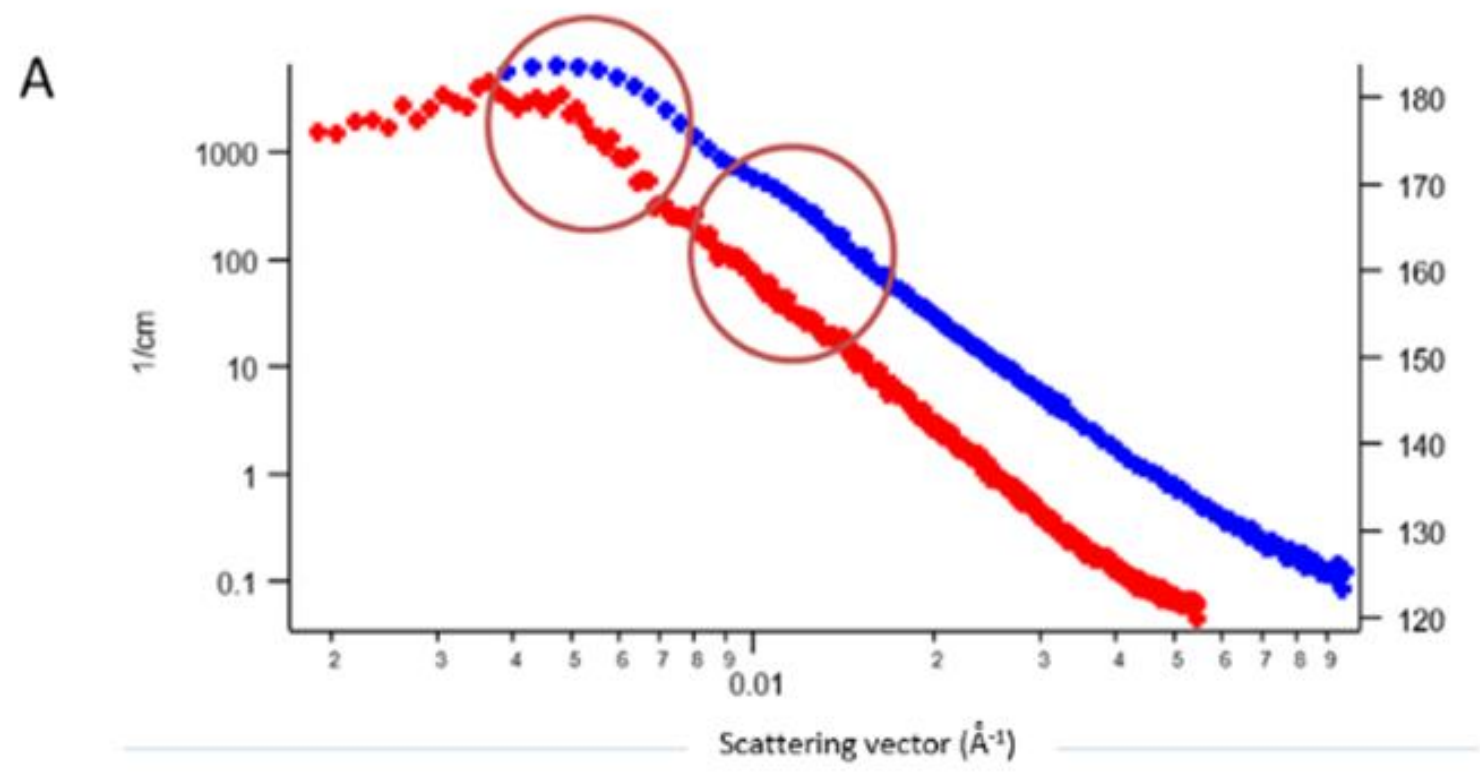

B

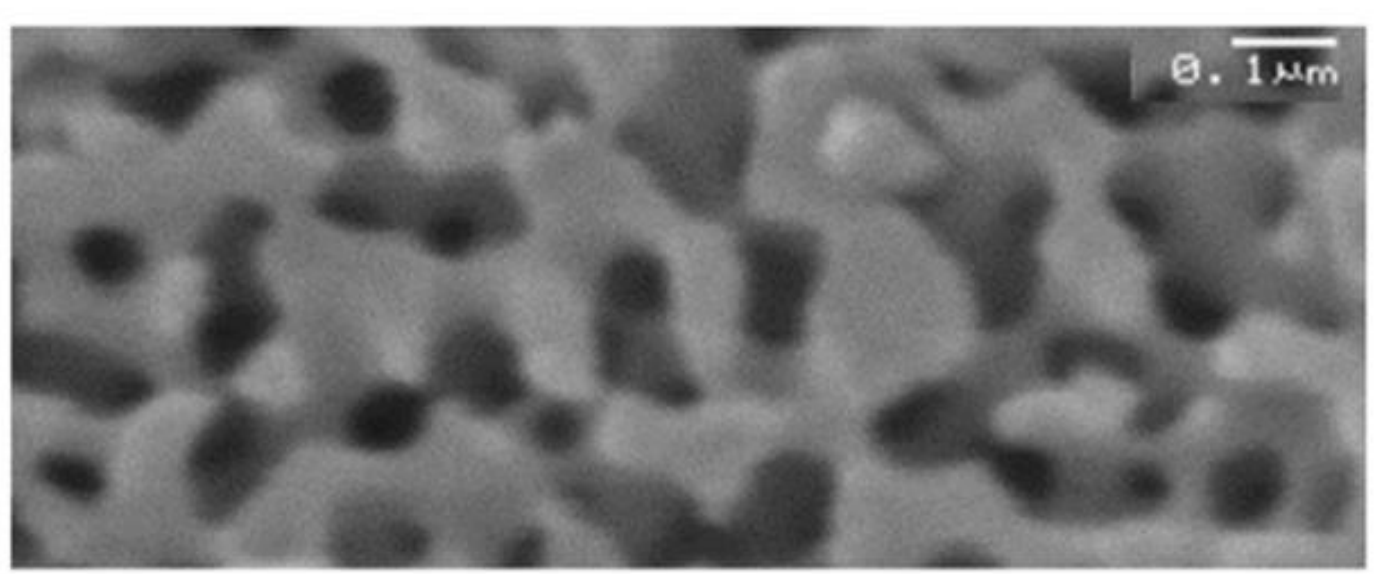


Figure 3

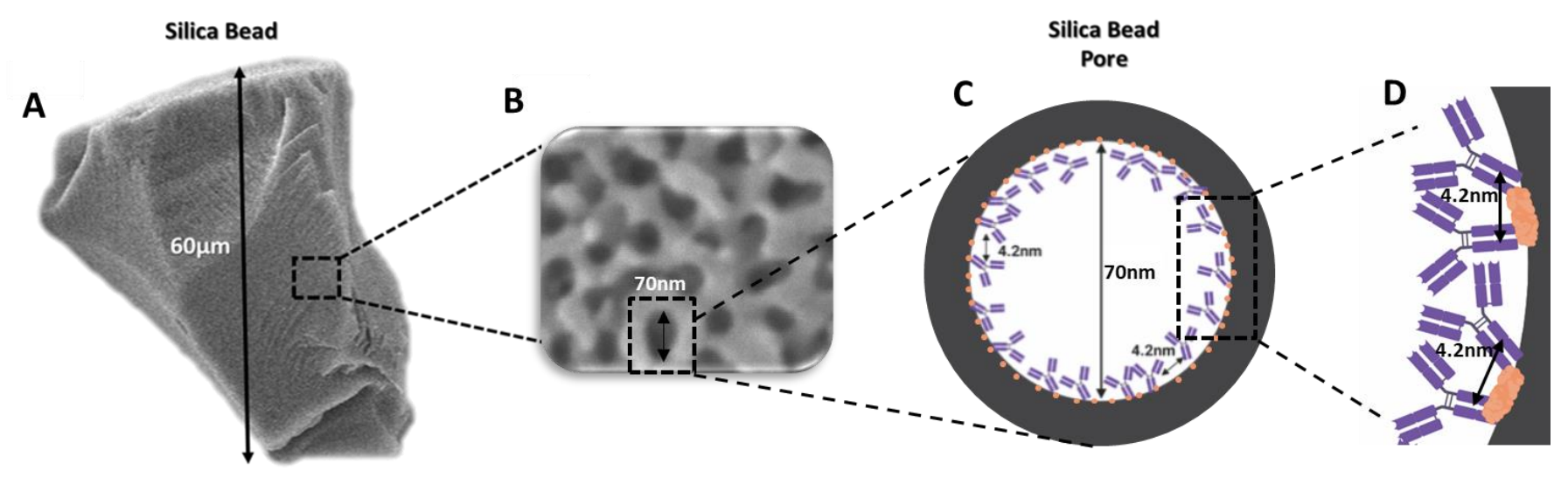


Figure 4
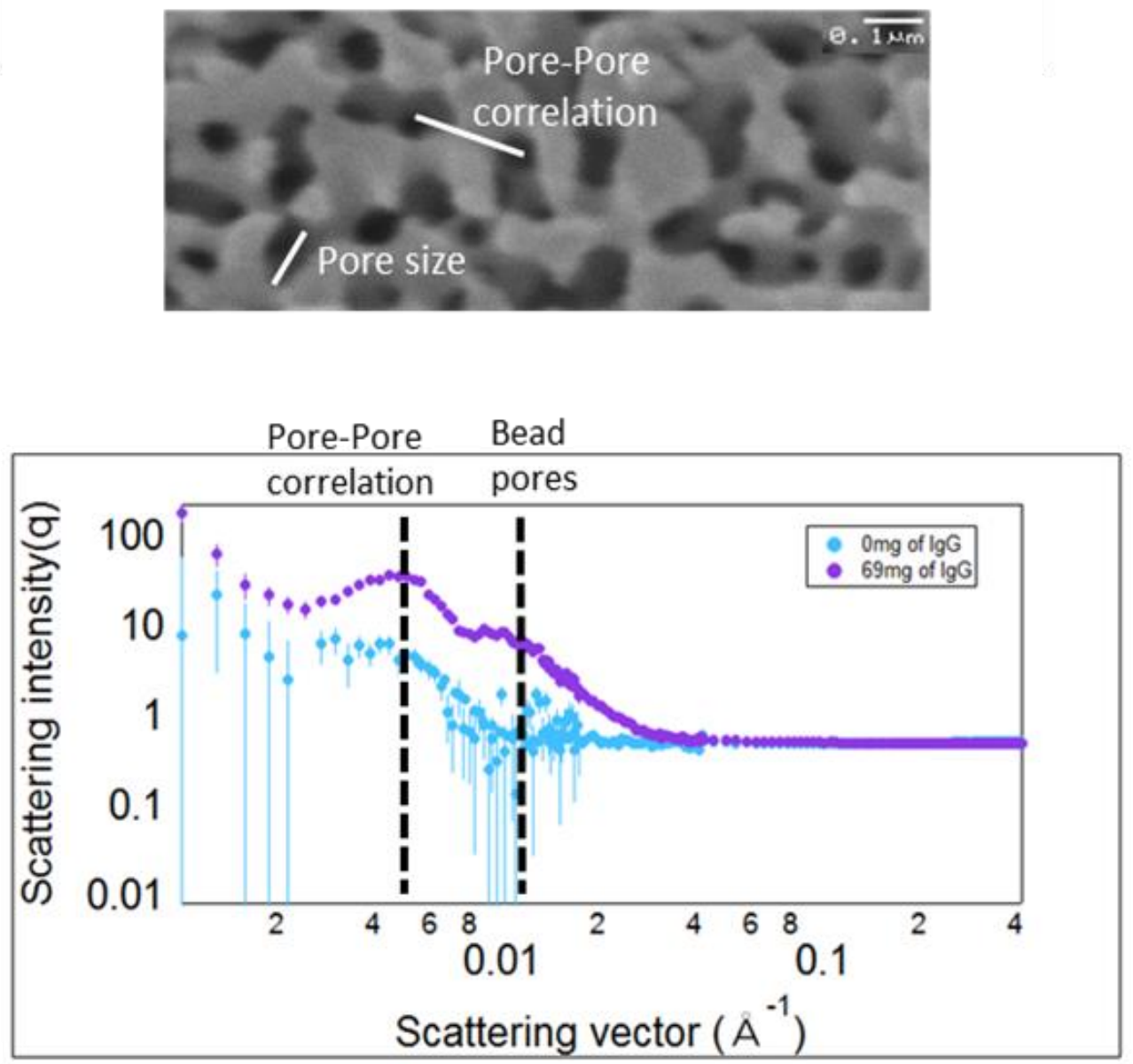
Figure 5
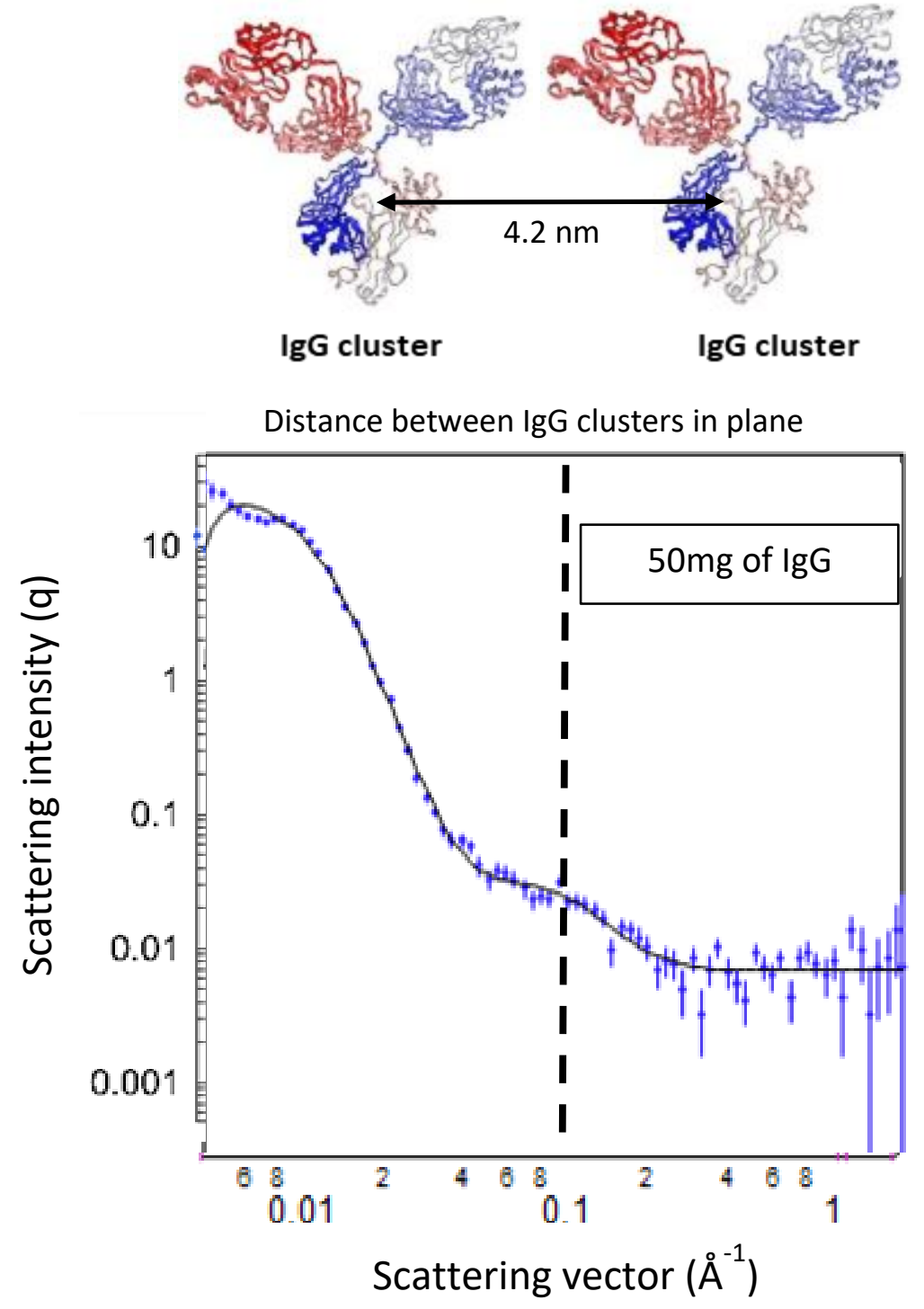
Figure 6
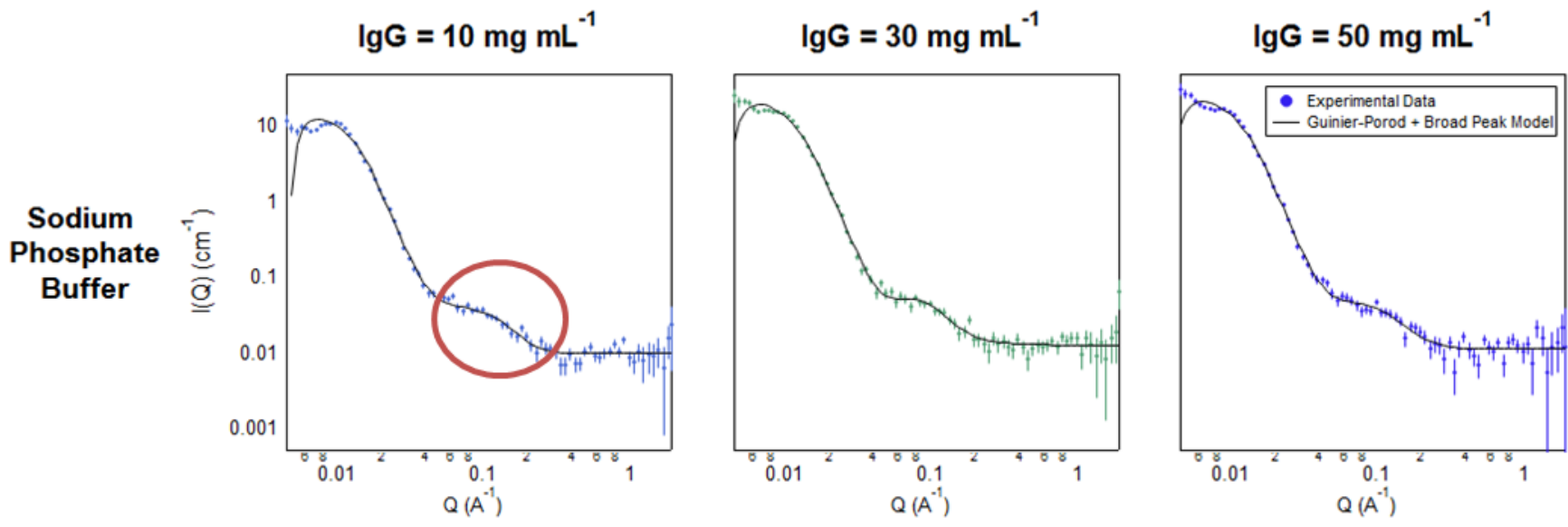
Figure 7
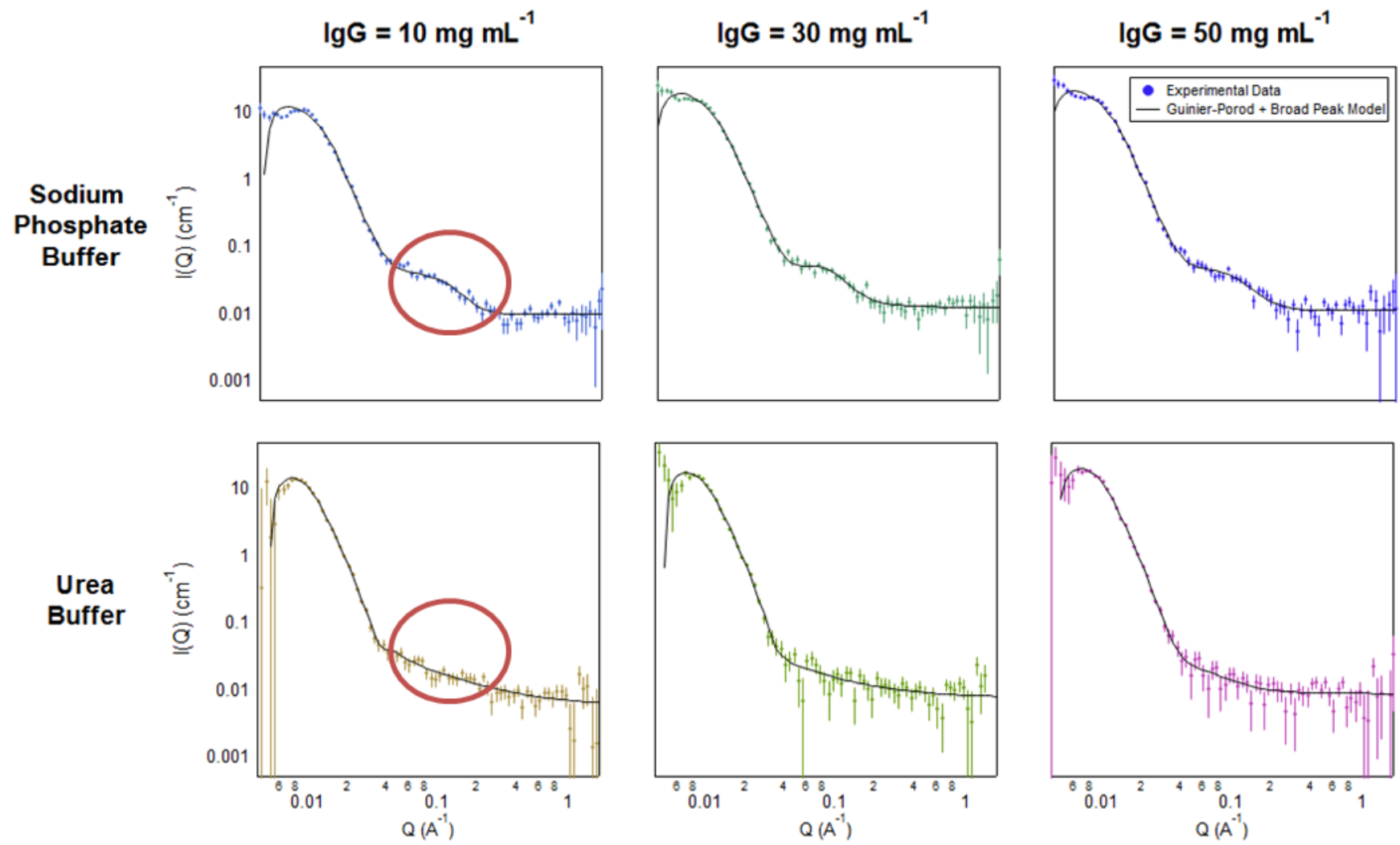
Figure 8

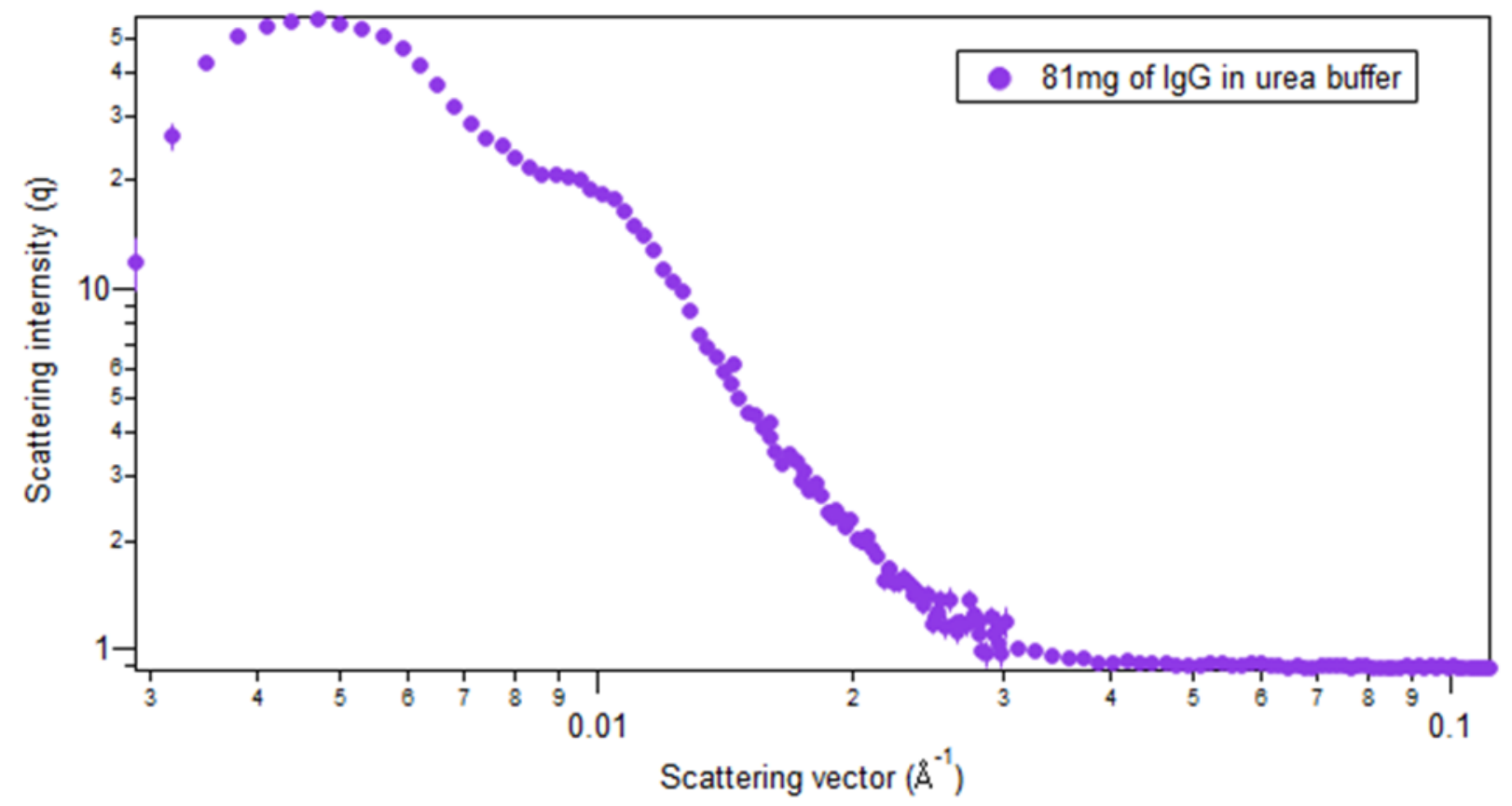

